\title{
US 2012 Live: when the classroom becomes a newsroom.
}

\section{Introduction: making it real}

One of the main aims of the journalism curriculum is to replicate the demands and pressures of a real newsroom, which as a result fosters a practical and applied approach to teaching and learning, and enables institutions to expose students to realworld experiences from the outset. Indeed research from the United States in the 1990s shows that there is a direct link between the particular type of university curriculum and employment opportunities. Feldman concludes that journalism students who have been involved in some form of experiential learning at university are more likely to get a job when they graduate (1995: 26). In today's climate where staff reporter positions are increasingly hard to come by, this assertion is likely to hold even more true.

Experiential learning is obviously a well-established approach within higher education, and journalism is no exception. Indeed, by its very nature, journalism education is largely practice-based. By living a professional experience, students have the opportunity to 'learn by doing' (Dewey, 1915). However, whilst the benefits of experiential learning have been well documented, what actually constitutes a model of experience can differ greatly depending on the context and the specific exercise(s) involved (Beard and Wilson, 2013; Gentry, 1990). It is therefore important to stress that a practice-based approach to teaching and learning does not automatically mean such an approach will be experiential. Indeed it is Gibbons and Hopkins (1985) who ask, 'How experiential is your experience-based program?'.

This question has been at the centre of journalism education research for many years (Mathews and Heathman, 2014; Lamb et al., 2010; Rhodes and Roessner, 2008; Steel et al., 2008; Cass, 2002). However, as modern newsrooms converge and become multimedia, the question takes on new dimensions. As most professional journalists, who once were print or broadcast specialists, now work across video, audio and text, universities have been struggling with how to replicate the industry and its new and rapidly evolving workflows.

News day practice, whereby groups of journalism students produce real news programmes in real time, have become a staple of J-school curricula (Mathews and Heathman, 2014; Lamb et al., 2010; Rhodes and Roessner, 2008; Steel et al., 2008; Cass, 2002). These news days vary greatly in character, depending on the particular 
institution, the individual programme and timetable, and the resources available. Therefore, the authenticity of these news day exercises varies widely. For example, is there a real audience for the news being produced? To what extent are the students working in a multimedia fashion? How much emphasis is placed on producing 'onthe-day' stories (meaning there is very little time to prepare in advance)? Do the deadlines in place actually replicate those of the industry? These are just some of the questions that will influence the depth of experience replicated in the classroom and determine the extent to which journalism students will be immersed in real-world experiences. This article argues that the level of authenticity of an experience is directly linked to its quality, and as a result, to the overall learning process.

Through an evaluation of live converged news coverage of the 2012 American Presidential election at Bournemouth University, it will be argued that the more 'real' the context, the more authentic the experience and the deeper the learning. This may appear to some as an uncontroversial assertion, but as many news days can be simulations without connections to the outer world and a specific audience, this statement will have particular resonance for J-Schools and their curricula (though there will undoubtedly be implications for other specialisms, where attempts to replicate 'reality' in the classroom can also be problematic).

Furthermore, it was the sheer size and scale of the US 2012 project, which sets it apart from other news day practice. It was a multifaceted and multilayered exercise, which allowed students the freedom to engage according to their own learning styles. Some devoted a few hours to produce a singular news article, others stayed up all night to report the election results. In addition to enhancing employment opportunities (Mathews and Heathman, 2014) or cementing an understanding of the notion of convergence (Lamb et al, 2010; Steel et al., 2008), US 2012 was an experience, which allowed students to engage with an authentic environment that was not only unfamiliar or challenging, but one that also involved a great deal of jeopardy. As a result, students felt empowered, motivated and proud.

It is important to note that the plethora of literature on experiential learning theory has a tendency to focus on the process of learning and reflection, rather than on the creation of the actual structure of the experience itself (Beard and Wilson, 2013; Boud et al, 1993; Gentry, 1990). In other words, the literature deals more with how the notion of experience can become invaluable for deep and meaningful learning, 
and less with the practicalities of creating this worthwhile experience in the first place. It is Gentry who notes how components of experiential learning 'must be delineated so that the necessary conditions for proper learning can be specified' (1990: 9).

However, it is not the purpose of this article to separate the notion of experience from learning. On the contrary, the relationship between learning and experience is key (Beard and Wilson, 2013; Moon, 2004; Kolb, 1984). Instead, the aim is to evaluate a specific and practical pedagogical approach that can foster and develop such a relationship. It is Criticos (2000) who argues we do not learn from experience alone. In line with Kolb (1984), he suggests that the experience must be processed in order that knowledge can result from it. What this article does argue is that the impact a particular context can have on learning is an under-theorised aspect of the experiential process.

\section{Keeping it real: a pedagogy for experiential learning}

Experiential learning has undoubtedly developed both as a theory and a practice over the decades. It has progressed from Dewey's original conception into something rather more complex: the four-stage cycle proposed by Kolb (1984), which has also since been developed by many other scholars (see Beard and Wilson, 2013; Moon, 2004; Boud and Walker, 2000; Dennison and Kirk, 1990; Cowan, 1998, Gibbs, 1988). As McGill and Warner Weil have noted, experiential learning is a term with 'a spectrum of meanings, practices and ideologies' (1989:3).

This article does not seek a unified theory, but instead offers an enquiry into the range of meanings available, and investigates how authentic experience can be created in the classroom in order to enhance the overall learning process. Silberman describes experiential learning as 'sticky learning' (2007: 4):

'When it is done well, it adheres to you. Participants will usually forget a great presentation, but they often remember a great experience' (2007:4).

Indeed experiential learning is a process-oriented concept, and whilst there are many definitions available, one of the most useful is that of McGill and Warner Weil, who see experiential learning as: 
'The process whereby people individually and in association with others, engage in direct encounter, then purposefully reflect upon, validate, transform, give personal meaning to and seek to integrate their different ways of knowing. Experiential learning therefore enables the discovery of possibilities that may not be evident from experience alone' (1989: 248).

Active learning is an essential ingredient of this experiential model (Beard and Wilson, 2013; Beard, 2013; Burnard 1991; 2002). Through experience 'we learn by taking part', whereas in the more traditional approach of lectures, 'we are more passive; we adopt knowledge' (Burnard, 1991: 217). An emphasis must be placed on the experience itself, which is usually active in some way, or more active than other areas of the curriculum (Beard and Wilson, 2013; Moon, 2004; Davies and EasterbySmith, 1984). However, this article argues that an experience, which moves beyond active to something that is real and authentic, has potentially a deeper impact on the learner.

Beard and Wilson (2013: 142) highlight how the notion of reality is complex. An experience can be real depending on the specific exercises, people and location involved, but reality can also extend beyond physical activities and space to emotions. As a result, it is therefore argued that it is useful to think of reality as a spectrum. The extent to which an experience is authentic will depend on how much and which aspects of the experience itself are real. For example, a simulation may provoke real emotion, but this emotion will be stronger and arguably provoke a deeper reflection if the experience is grounded in the real world. This position does not reject or ignore the potential of games, simulations or other 'less real' experiences, which have been well documented by Beard and Wilson (2013). It simply suggests that the more real and authentic an experience is, the greater the potential for learning.

Moon acknowledges that learning can occur from some experiences more effectively than others (2004: 113), and Davies and Easterby-Smith (1984) argue the best experiences are derived from novel situations. The Association to Advance Collegiate Schools of Business (AACSB) also says the experience should be characterized by ‘variability and uncertainty’ (cited in Carter et al., 1986: 3) and Beard and Wilson assert that experiences must have elements of 'risk' (2013: 131). Experiences, which are more authentic or real, therefore make these features more attainable. 
Experiential learning must also provide adequate opportunities for learners to reflect on their experience (Beard and Wilson, 2013; Moon, 2004; Boud and Walker, 2000; Newman, 1999; Cowan, 1998; Schön, 1987; Kolb, 1984). Whilst most scholars would argue the experience in experiential learning is not mediated (Moon, 2004), this article would support Beard and Wilson's claim that some form of coaching or facilitation is essential to encourage reflection (2013).

Kolb (1984) describes four different styles or preferences for learning. This refers to four different ways of experiencing the learning process. An experiential learning environment will allow students to engage with a subject from any of these four standpoints. Crucially, however, it is important to remember that this is of course a cycle, so educators must empower learners to complete the circle, no matter from which point they prefer to depart.

The Kolb cycle has been heavily criticised. Some scholars believe the cycle is too simplistic (Moon, 1999 and 2001; Rowland, 2000, Newman, 1999; Jarvis, 1987) or others formulaic (Marsick and Watkins, 1990). Seaman and Rheingold describe the experience phase in the cycle as 'messy, contingent and untrustworthy' (2013: 158), but this is precisely because of its subjective nature. It is often overlooked that Kolb's cycle 'takes into account that all students have different learning styles' (Rhodes and Roessner, 2008: 305). Indeed, 'visual, auditory and kinesthetic learners have the opportunity to excel in experiential learning environments' (Rhodes and Roessner, 2008: 312). In the experiential model, immediate personal experience is the focal point for learning. As pointed out by Kolb, personal experience gives 'life, texture, and subjective personal meaning to abstract concepts' (1984: 21).

Moon proclaims it a 'shame that Kolb did not say more about the nature of the observation and reflection stages’ of his cycle (1999: 84). Boud and Walker (1990) write how these stages bring more order to the experiential learning process, but Seaman and Rheingold (2013) urge caution in separating experience from reflection. This is an idea that Cowan (1998) has drawn upon. Cowan redraws the Kolb cycle in order to incorporate more detail of the reflective processes based on Schön (1987). His model, which he describes as ‘an over-stretched spring’ (Cowan, 1998: 37), aims to show that reflection is actually an ongoing part of the experiential process, occurring before, during and after any given task or experience.

One of the biggest challenges when adopting an experiential learning approach is facilitating opportunities to ensure learners are able to reflect in a deep 
and meaningful way (Moon, 2004). What can be even harder, is monitoring this process to keep track of what students are actually learning.

The subjectivity of experience makes it virtually impossible to effectively measure how deep one's learning may be as a result. US 2012 was no exception. Regular feedback is needed as an opportunity for both staff and students to reflect together and keep track of this process as much as they can. Kolb (1984) suggested that learners would somehow move through his cycle of learning, but this will be different for each student. Some may complete the circle, others may not. As educators, we want to control the learning experience to ensure it is valuable for everyone, but the holistic nature of experiential learning must be recognised. Newman has criticised Kolb’s cycle for being:

'...too ordered, too regular, too predictable. It seems to imply an imperative: that we must move through the cycle, that we must move on to the next stage, rather than letting experiences enter into our souls to rest there, develop, change and influence us in some more disordered, unexpected way’ (Newman, 1999: 84).

Indeed experiential learning can be behavioural, action-based, cognitive or social. All of these can occur simultaneously, since the experience itself has many dimensions. Perhaps this is the only assurance for educators. We cannot assess how each individual will engage, or what they will actually take away. All we can do is make the experience as authentic as possible. Therefore, the greater the authenticity, the greater the subjectivity, and the greater the subjectivity, the greater the inclusivity. In other words, the more real the experience, the greater opportunity for the inclusion of all styles of learner. In such a context, educators become facilitators rather than lecturers. This ensures that the experience becomes multi-dimensional and includes multiple entry points for learners of all needs and abilities.

\section{Making it real: US 2012 as an authentic 'live case'}

Gentry formulates a continuum of pedagogies that progress from those with 'low experiential learning potential' such as lectures to those with 'high experiential learning potential' such as work placements or real-world experiences. These, he calls the 'live case' (1990: 17). Gentry asserts that experience will lead to learning, but 'it must be under the right conditions’ (Gentry, 1990: 9). 
In November 2012 the authors, one a multi-media journalist and the other, a print and online journalist teamed up to lead a co-curricular converged newsroom exercise covering the American Presidential Election. 300 students from 13 undergraduate and postgraduate courses were involved with 26 members of staff. The project, which lasted 6 weeks, culminated in ten hours each of live television and radio, both streamed from our dedicated website. The project's radio coverage was also broadcast on a local station, Hope FM.

The US 2012 website was live for the nine days previous to the election date (ten days in total), providing news, features and analysis. 176 articles were written (on average 17 a day for 10 days), 35 radio packages were produced and 30 TV reports were broadcast. The coverage, which also involved a ten-hour live blog, involved 50 live discussion guests (both in the studio and via Skype or ISDN from the USA) and involved a partnership with students at the University of Massachusetts in Amherst, who acted as a team of reporters on the ground. During the 10 days of coverage, the website received more than 20,000 hits and almost half of those were on election day itself. This is far fewer than professional news sites receive, but far larger than student journalists at Bournemouth University are used to. In comparison, during a standard practice-based news day within the curriculum, the website receives around 900 hits in a 24 hour period. Furthermore, the TV and radio bulletins do not have a live or real audience. They are not streamed and are only watched or heard by academic staff. The exposure to the real world, and the sense of jeopardy or risk this authenticity created, was therefore one of the major experiential factors of US 2012.

It is worth highlighting that within education the multimedia approach of convergence journalism (whereby reporters produce stories simultaneously in text, audio and video) was pioneered at Bournemouth University. It became the first British journalism school to train its students in multimedia techniques in 1992. Robinson in her call for more relevant journalism education for the digital age makes the point that the implementation of convergence in universities has been 'cautious, informal and spotty’ (2013: 1), yet at BU there has been a converged journalism unit in place for both undergraduates and postgraduates since 2008. Typically, these involve up to 100 students on any one news day producing broadcast news bulletins and online coverage in small groups and in real-time. The US 2012 coverage was therefore an extension of this, but as one second year multimedia journalism student said: 
"US 2012 was unlike any other news day. I learned more in this one week than in my entire first year. There was just more at stake so I think everyone worked harder."

This echoes the findings of Steel et al. (2008) who conclude that after a similar exercise:

In just a few days, the students appeared to have hit precisely the problems and benefits that have made convergence such a tough - yet rewarding - nut to crack for working journalists (Steel et al., 2008: 330).

Indeed the Broadcast Journalism Training Council (BJTC), which is one of two bodies that accredits journalism programmes in the UK, state that:

Most employers want to see graduates with initiative and commitment and the professional skills to effectively gather information and to tell a story, whatever the medium (BJTC, 2014).

This was at the heart of US 2012. Students were divided into multimedia teams to replicate a real converged newsroom. Leadership and editorial roles were devolved and students themselves decided which aspects of the election to cover and how. They held daily editorial meetings, where journalism staff offered guidance and pointers, but overall students had complete freedom to decide which issues they felt were of most importance. They responded to on-the-day events in the various campaigns, but also produced reflective multimedia features on some of the key issues. Students worked individually as well as in groups. They also constructed multimedia graphics to explain how the US electoral system works and investigated key people to interview from all sides of the political divide.

Converged news days can be experiential, as was explained in the introduction. They are very much hands-on, but often there is little jeopardy involved for the student. These days are usually meticulously planned, and although they are produced in real time and based on real events, they can be largely predictable simulations with no audience. Furthermore, in rural Dorset, where the university is located, breaking news is a very rare occurrence.

US 2012, conversely, provided many more opportunities for learners: it allowed students to engage with a real and important event in international affairs; the outcome of the election was unpredictable; there was a real audience; students had to respond to breaking news; election programmes were longer and different in style to 
those normally produced; students worked with peers from other disciplines; the coverage was rolling, and in direct competition with just about every other news organisation in the world; students worked in a shift-pattern (including all night), which reflects the reality of professional journalism; there was a necessity to monitor and wrap real-time news agency feeds; students had decision-making authority; students had the opportunity for real live reporting (we had several outside broadcast locations around campus, from the Students' Union to our 'Social Media Centre'); presenters were able to interview real people live (including key players like the Presidential candidates for the Greens and Libertarians) and often had to carry these out at the last minute and with no preparation; students were operating outside of their comfort zone; students had the opportunity to live-blog a real time event and there were more technical opportunities to vision mix or work in the gallery, for example.

All of these features encapsulate Gentry’s ‘live case’ pedagogic model (1990: 19) and created a real experiential environment for students that embodied the definition provided by McGill and Warner Weil in the previous section. US 2012 was therefore 'participative, interactive and applied' (Gentry, 1990: 97). It allowed 'contact with the environment, and exposure to processes that are highly variable and uncertain', and it involved 'the whole-person', whereby 'learning takes place on the affective and behavioural dimensions as well as cognitive dimensions' (Gentry, 1990: 97). The unpredictability of the event, and therefore the 'risk' involved (Beard and Wilson, 2013: 131) added to the authenticity, and to a certain extent, in some cases anyway, to the quality of journalism being produced. Staff involved noted how students were successful at working to the tight deadlines involved in the project, producing stories that displayed solid writing and production skills. Students were also engaged with events in the US and suggested well thought through feature ideas. The level of pride involved was noteworthy too. Students were determined and conscientious and worked long hours to complete their individual stories. In short, the student body appeared to take this exercise much more seriously than the regular news day.

US 2012 was awarded Best Live Programme and was runner-up for Best Factual Programming and Best Male Presenter at the British National Student Television Awards in 2013, and was also awarded Best Radio News Day by the Broadcast Journalism Training Council in the United Kingdom. The Dean of the 
Bournemouth University Media School described it as "one of the most ambitious projects” ever undertaken, though US 2012 was not without its problems.

\section{Evaluating US 2012}

The evaluation of the project offers a qualitative analysis of staff and student feedback. Respondents were asked to fill out an anonymous unstructured questionnaire, which had a 35\% response rate. Of the 326 involved, 114 people responded. In addition, a total of 20 semi-structured interviews were also conducted with key staff and students. These included a combination of those who were involved with the project for the longest and shortest time, and those who had both leadership and non-leadership roles. Those interviewed were asked to reflect on the overall project (including motivation for taking part, the organisation, the scope, available resources, etc) and how they felt it impacted on their learning. Respondents were also asked to consider their own engagement with and contribution to the exercise, and to consider any possible links with existing units on the curriculum. What were they prepared for? What was unexpected? Which unit best prepared them for the exercise? How did the exercise compare to usual news day practice? In addition, they were asked to comment on interaction with staff and students and they were given the opportunity to add anything they felt important to comment on.

The authors acknowledge that the numbers involved are not extensive, but as Denscombe notes, even a small sample has a potential to offer 'valuable and meaningful insight' (1988: 25). The evaluation below has been categorised according to four major themes emerging from the feedback, and each category is placed under the umbrella of the reality and authenticity of the project, which was the biggest recurring theme of the exercise.

\section{Professionalism and Employability}

The overwhelming reason for students choosing to take part in this project was for their $\mathrm{CV}$, which is clearly linked to the reality and authenticity of the project. One $2^{\text {nd }}$ year television production student described the authenticity of US 2012 as a “once in a lifetime opportunity." Another $2^{\text {nd }}$ year described the project as the "first chance to practice real journalism, which has confirmed my career choice.” It also gave students the chance to produce good quality work for their National Council for 
the Training of Journalists Portfolio, which forms part of their professional journalism qualification.

Some may assume that the barrier to 'going live' is lower than ever with the advent of new and low cost technologies. Admittedly, there has been an explosion of so-called 'citizen journalism' and the majority of students have their own blogs and social media accounts where they publish their material on a regular basis. However, for a journalist, the overall aim is to publish for the mainstream, or at least reach as many people as possible, and it is incredibly difficult for students to get their work published on credible news sites. Furthermore, any journalist will tell you that there is a world of difference between writing one article or producing a video for the web (which student journalists do on a regular basis) and being involved in a team of 300 people working on the same story, and a major international story at that. Our project aimed to replicate a mainstream newsroom during a major world news event, and this is something that students found so appealing.

The project leaders had anticipated the professional benefits and employment potential for participating students in advance. Such an assumption is supported by the research of Mathews and Heathman (2014). A partnership with the local radio station Hope FM was established so students (on the radio at least) could have the benefit of a real audience, instantly separating this work from that on the rest of the course, which is usually produced only for classroom assessment. The station manager said in a written message to students:

"I was impressed by the entire exercise and you should be proud. The programme was insightful and captivating. We look forward to future collaborations."

The project leaders also invited former BBC Washington correspondent turned presenter Stephen Sackur to lead a workshop, which was extremely popular. He took questions on US politics and held a masterclass on presenting. Other practising journalists were used as mentors during the coverage. This also added to the reality and authenticity of the project. Clear and relevant links to the real world were established through these interactions with key, even 'star' journalists.

As Beard and Wilson (2013) note, the degree of subject relevance in higher education is important. This will undoubtedly come as no surprise to most lecturers. Nor will the findings of Beard's research from 2005, when he concluded that 
'relevance' and 'reality' were what students wanted more of in class. Beard and Wilson state:

Experiential learning is the sense-making process of active engagement between the inner world of the person and the outer world of the environment (2013: 4).

They go on to show that deeper learning experiences can occur when students are removed from the classroom. They stress the importance of a change in physical space, which they argue is necessary to enhance the experience (Beard and Wilson, 2013). This would support Fazey and Marton's idea that students react positively to unexpected changes around them (2002). However, it is possible to change the working environment and physical space, without having to go outdoors or move into a new space completely. The classrooms involved in US 2012 underwent a makeover for the project. Furniture was moved, new kit was installed and they became professional, working converged newsrooms, where text, video and audio teams work together. This article would suggest that it is better to think of 'the outer world of the environment' (Beard and Wilson, 2013: 4) not just in terms of physical space, but in terms of connections to real people (those not connected to the university or the institution in question) and to the professional working world.

The pace of working in a busy newsroom and the desire to contribute to the success of a collective product certainly appeared to minimise the risk of boredom in the classroom, which can be damaging for students (Mathews and Heathman, 2014; Mann \& Robinson, 2009). It was also because of the authenticity of the project that it became very common for students to express a sense of pride at belonging to US 2012, and at seeing their work go live on the website or be broadcast on TV or hear it on radio:

"It was so much fun and was an extremely valuable experience. I learned a great deal and now feel so much better placed to work in a real newsroom. It was stressful, yet fun and more exhilarating than I could have imagined. This is the highlight of my three years at Bournemouth."

$$
\text { ( } 3^{\text {rd }} \text { year multimedia journalism student) }
$$

Furthermore, not only did students seek to improve their professional skills set and employability potential, many viewers commented on the professional nature of 
the content the students were actually producing. The reality and authenticity of the exercise motivated the students to perform. One senior member of staff said:

"I logged on to the website and stayed hooked til 3am - the energy and professionalism of all the students was quite amazing."

A Guardian journalist that took part in the project commented:

"It was great fun. I was totally impressed by how cool all the students were during a breaking news event and by how knowledgeable they all were."

And the Dean of the Media School said:

"Having covered the U.S. elections live for Reuters in America, I was deeply impressed by the professionalism of our students. What impressed me most was the way they were able to handle the long waiting game where there is, in fact, so little news to cover. They did this through meticulous planning and shooting of pre-canned features and imaginative ad-libbing."

\section{$\underline{\text { Skills and knowledge }}$}

There was an overall sense that students learned a lot during the US 2012 project, though students clearly lacked confidence in some areas and even expressed anxiety in others. One student described how he felt he learned more in the 24 hours of election coverage, than he did in his first two years of his journalism degree. Such comments highlight the effectiveness of news day practice, when that news is based on real events (in this case one of the most important news stories of the year) and involves real people. Such was the intensity of the US 2012 project that students did indeed feel they learned more than they do in the classroom because they were exposed to and learned how to deal with unpredictability, and this is something hard to recreate in a simulation.

The sheer size and ambition of the project was always going to be a steep learning curve for everyone involved, but it is clear that students were able to learn new skills and enhance those they already developed. This latter point should not be underestimated or ignored. The previous experience of the learner should be recognised as an important factor in experiential learning (Beard and Wilson, 2013; Noble, 2002; Andersen at al., 2000), which is not just about acquiring new skills, but 
also about those already part of one's armour. It is the realisation of the individual needs of each learner. This is because our own genetic make-up and personality make each experience we undergo unique. Respect for this concept can help to serve the 'self-directive potential of the learner' (Anderson et al., 2000: 227-228). This does not mean drawing up an individual curriculum for each student. Instead, students should be allowed to find their own way through an experience, though as we will see below, some guidance might be needed.

Fazey and Marton (2002) show how learners learn more effectively when they are confronted with situations that challenge them to cope with a range of variations in experience. Boydell (1976) also argues that the learner will actively seek out meaning. However, an element of structure is key. Students need to be aware of what to reflect on and guidance can be appropriate in this regard (Beard and Wilson, 2013; Moon, 2004).

Furthermore, if students lack previous experience, then this must also be taken into account. One first year multimedia journalism student commented how the process was "learn as you go,” a kind of sink or swim approach that left him feeling “inexperienced and lost." He added support for his year group (who had only been on the course for six weeks) was inadequate. This is undeniably something that should have been better considered at the design phase.

The TV coverage provided most obstacles on the night and those on the TV team described feeling “insecure” and “anxious.” Snell (1992) draws attention to the painful nature of learning in an experiential environment. Beard and Wilson also highlight the 'unpredictable nature' of life and argue not all experiences will offer positive opportunities for learning (2013: 34). They suggest an individual's mind must be open to the learning potential and argue a person can be negatively affected by bad experience. Moon, however, argues that the 'unlearning' from experience can be more important than learning more (Moon, 2004: 113). This implies that learning by mistake will ensure such mistakes never happen again. For example, pre-filmed television news reports need to be correctly labeled in the scripts used for broadcast. That is to say that the file name inputted by the student producer into the digital broadcast system must match exactly the file name of the report on the server, otherwise the director in the studio gallery is unable to play and broadcast the report. However, one student confessed that it was only when she had failed to do this and witnessed the consequences (a flummoxed presenter, an 
extremely angry director, dead air and a confused audience) that she realised the necessity of what lecturers had told her time and time again. These are the 'miseducative experiences' first outlined by Dewey (1938), but of course, all of this will depend on personality.

The opportunity for an individual to react according to his or her own character is arguably therefore the greatest strength, but also the biggest weakness of the experiential learning process.

At the other end of the scale, it was inspiring to see students from different disciplines working together (often more effectively than the staff!). BA TV Production students and BA Multimedia Journalism students commented on how much they learned from each other, for example - the former more technically minded, the latter arguably better with visual storytelling. Experiential learning is therefore not solely based on the individual. McGill and Warner Weil also conclude that the learning process occurs in 'association with others' (1989: 248).

For this particular exercise, background knowledge was also essential to ensure each student could reach his or her full learning potential. It was also useful to prepare them for the enormity of the task that lay ahead. The project leaders were well aware that the majority of students were largely out of their comfort zones talking about US politics. A programme of lectures and workshops was drawn up as a result to introduce students to the American political system and they were given adequate opportunity to raise any questions with regular tutorials held by the staff. The senior editorial team (SET) and presenters were also set group tasks each week so they could work together and investigate the current issues of American politics further. They were also tasked with finding potential interviewees and story angles. This extra support was all devised as part of the structure phase of our project and was welcomed by students as "extremely useful" and even "vital." So while experiential learning is often defined as being thrown in at the deep end, some element of preparation is needed (though this will of course depend on the exercise and experience involved). In their typology for a basic experiential learning programme, Beard and Wilson also highlight the need for setting targets, goals or objectives from the outset (2013: 131).

Overall, students felt their knowledge was significantly improved by the project. Many expressed how it had had a positive impact on the rest of their studies, 
especially when it came to meeting deadlines, writing more quickly, and generally becoming more confident with people in a highly pressurised environment:

"It was a fast-paced and challenging environment and the outcome was rewarding."

( $2^{\text {nd }}$ year multimedia journalism student).

"I got a higher mark for my last assignment than I would normally get. This is down to what I learned from US 2012. My writing is much better."

( $2^{\text {nd }}$ year multimedia journalism student).

When pushed about what it was about his writing that was better, the student explained that he was able to write more quickly. Writing quickly and to tight deadlines is obviously a core skill in journalism. US 2012 had given him much more practice at writing under pressurised conditions. He also explained that he had a better idea of how to read information and summarise it in a much more "succinct and accessible fashion.” Students were producing material for US 2012 at a rate not expected in the classroom, and this testimony highlights the positive impact this intensity and opportunity to practice had, allowing students more opportunity to develop core journalistic skills.

\section{Communication}

The feedback from the event shows that clearer communication channels needed to be opened. It was at times difficult to ensure that 300 students over four floors of the building were on the same page in terms of headlines and results, for example. One of the senior team said she wished the project had been "more collective." It became "too competitive at times," she said, and teams were not sharing information and guests. Whilst this is a flaw in the structure, it does reflect the reality of a newsroom where individual teams do become rivals. However, the setting of ground rules may be appropriate to ensure learners can fully engage with the learning process and be able to fully reflect on both their own involvement and on the environment around them (Beard and Wilson, 2013). As Moon notes, 'experiential learning takes effort' (2004: 113).

The situation was not helped by the email server going down at the start of our election night coverage. Teams relied on walky-talky radios to communicate, but these had a limited reception. The breakdown in communication was detrimental to 
the coverage at times, with the $\mathrm{Hub}^{1}$ failing to let the broadcast teams know about guests waiting to go on air. The result was "confusing” according to some, but this adds to the 'variablity' and 'uncertainty' (AACSB in Carter et. al 1984) or 'risk' (Beard and Wilson, 2013: 131) of the experiential exercise, where students discover the 'messy' situation and authenticity of the real world (Boud et al., 1985). Such breakdowns in communication required quick thinking and good problem solving skills, which only added to the educational and experiential value of the exercise.

The senior team displayed strong editorial leadership throughout the project. They worked hard to motivate their team, though they did struggle on occasion. As the project was co-curricular and voluntary, commitment from some students was sometimes lacking. The SET described in their feedback how they felt unable to force people to do anything, especially if they were a final year student with their final coursework project and dissertation looming:

"I wish I had been more at ease delegating and trusting others to come up with the goods."

( $3^{\text {rd }}$ year multimedia journalism student).

Other members of the team describe how both the senior editors and the staff were too busy on the night to help, and one student felt power was abused by some.

However, perhaps one of the biggest communication failures of the whole project was the breakdown and confusion generated from the partnership with the University of Massachusetts. The staff involved had decided at the start of the project to let the student editors lead on this at both ends of the Atlantic, but the end result was that not much was achieved in the run-up to election day. The plan had been for UMASS to generate some video and radio features for us, but these never materialised, probably because they were unaware of what was really desired. The staff involved failed to adequately monitor communications between the two teams. However, on the night of the election itself, UMASS provided hourly live coverage and really brought US 2012 to life in ways that would have been impossible without them.

\footnotetext{
1 The Hub was the heart of our newsgathering operation. It collated results, researched live guests, produced an internal newswire and acted as the assignment desk for reporters and correspondents.
} 
Overall, the US 2012 team worked extremely well together. It would not be an exaggeration to say that communication between certain staff members was strained at times, but most of those involved were working in their spare time, and technical support staff were under immense pressure as they went beyond the call of duty to ensure the website didn't go down or the live shows fall off air.

The relationship between lecturer and student also took on new dimensions. In their role as mentors and facilitators in this environment, the project leaders became peers to their students, this adding to the authenticity of the project. Professional boundaries were maintained at all times and at no time did staff lose any authority, however. In fact, there was the opposite effect. When things went wrong, students described how they felt:

"...disappointed that they had let down the lecturers after the time and effort they had put in... Lecturers were 200\% engaged and their passion and dedication inspired me. People were engaged with the teaching in a way they wouldn't have otherwise been if it had been part of a course unit. Lecturers helped shape not only the project, but our own personal development. Thank you for believing in me and trusting me."

( $3^{\text {rd }}$ year multimedia journalism student)

\section{Organisation}

There was only a six-week lead up to this project, which given the ambitious scope of US 2012 was not sufficient. Staff and students worked late nights and every weekend to make sure that everything that needed to be done was completed. There was a large sense that many involved in the project felt unprepared. There was certainly inadequate rehearsal time due to the unavailability of the TV studio in the weeks before the live show. This created a sense of insecurity in the TV team that they were not as prepared as the radio team, for example. The lack of rehearsal time and space definitely impacted on the night of the live coverage and resulted in both confusion and chaos at times. This was something the project leaders had been aware of during the design phase, and there was little option to do anything about it. It was a clear issue of resources, but adequate planning is essential.

There was a definitive schedule outlined to the students from the outset of the project. Deadlines were set every step of the way and students were guided through the process. This was a clear attempt to introduce structure or 'scaffolded' learning (Vygotsky, 1978) to the project in an attempt to ensure a deeper experience. However, 
these deadlines were often missed and set back as a result. The reason was often due to coursework assessment or dissertation preparation, which given the voluntary nature of the project, was just misfortune.

Arguably the biggest failure of the whole project was the lack of opportunity for group evaluation and feedback, especially during the actual election night. Whilst reflection is recognised as an essential part of the experiential process, feedback and evaluation, and their role in facilitating this reflection, are often ignored. Whilst the holistic nature of experiential learning is celebrated, learners will need some kind of mechanism for feedback. Tutors were able to coach students at various stages throughout the project and when they needed help on an individual basis, but it was ad hoc. With more than 300 students involved, we simply did not have enough staff. Indeed the staff-student ratio is bound to be an issue with an exercise of this size. A structure and schedule for adequate feedback therefore becomes essential.

Lecturers did hold regular tutorials on writing or offered advice on rough cuts of broadcast packages, but some students did not always feel able to seek out answers to their individual concerns and questions. There was undoubtedly a need for more staff to be available throughout the project. The voluntary nature of the project and the fact we were working through the night meant it was not suitable for some, but this is something we could have better prepared for.

Normally after a news day, it is common practice to hold a debrief, but after a full night of coverage and when most had already been in the building for 24 hours, this was not appropriate. Instead, the project leaders took to email to offer feedback, which was not ideal as there is no perception of how the email was understood or even if it was read. Gentry notes the absolute fundamental nature of feedback, which he says is:

'...critical for proper learning to take place after an experience. The student should not be allowed to conclude what was learned without receiving feedback... the debriefing session is crucial. Students need to articulate their perception of what was learned and the instructor needs to put things in a broader perspective' (Gentry, 1990:17).

In retrospect, then, it might have been better to schedule regular feedback sessions. For example, at the end of each shift on the website and at key points during the live programming. This is indeed a recommendation of Beard and Wilson's 
typology for experiential learning (2013: 131). Staff should also have been more available to students seeking help during the night. Another mechanism might have been to introduce a logbook or portfolio for the students, which encouraged them to chart and reflect on their engagement and production with the project as it progressed. This could even form part of an assessment, but there must still be opportunity for students to engage with staff for individual feedback. This is essential to facilitate a more effective process of reflection, but it does require a proper structure.

\section{Nine steps to making it real}

US 2012 was a co-curricular activity, tied to a particular historic event. As we have established, news days will already be a major feature of most J-school curricula, but the experiential benefits of an event on the scale of US 2012 are undeniable. It was much more than a practice-based news day. The scale of the project made it more real and more authentic and as a result there was much more at stake for the students.

An exercise of this scale cannot be executed regularly. There are too many constraints on time, space and other resources, so the scope to implement something like this into the curriculum is limited. It can, however, provide advice or inspiration for how to improve existing news day practice, notwithstanding that one-off news events also offer fantastic opportunities for special projects that may or may not form part of a unit. Simply generating an audience from outside the institution can greatly enhance the experiential process. With that in mind, this section offers some basic guidelines for those wishing to replicate and learn from the successes and failures of US 2012 and create a 'live case' of their own (Gentry, 1990:19).

\section{AUTHENTICITY}

The aim is to replicate reality. Give the students freedom. Allow them to become decision-makers. Find an event that will be important, that other news organisations will cover. There must be more at stake and there should be connections to the real world. Generate an audience.

\section{PLAN AND DEVISE THOROUGHLY:}

Planning is essential. There needs to be a clear timetable and structure that everyone can follow. There must be a clear picture of aims and roles for everyone. Allow 
adequate time to prepare staff and students in the run-up to the event. Make students aware of the aims and objectives of the project. Let them set their own goals.

\section{ENGAGE KEY PLAYERS ASAP:}

Exercises like these cost large amounts of money. Those in control of the budget must be courted early. Both staff and student leaders should also be identified. Who will be able to motivate others to join the project? Who can help with a senior organisational or editorial roles?

\section{ENSURE THERE IS ADEQUATE TECHNICAL SUPPORT:}

An exercise of this scale requires around-the-clock technical support. Who can provide that? Who will ensure adequate communications are in place? Who will deal with software failures and system crashes? Do you have the specific equipment in place to meet your requirements?

\section{ORGANISE STAFF AND STUDENTS:}

There must be clearly identified roles and regular meetings. Students need a clear hierarchy outlining whom they can turn to. Staff too, for that matter, need to know who is ultimately responsible and for what.

\section{MONITOR AND GUIDE PROGRESS:}

Experiential learning does not happen by magic. Consider a supplementary workshop or lecture/seminar programme. Ensure at least one member of staff is holding regular tutorials or is at the very least contactable.

\section{THINK IMPACT:}

Professionalism and employability will sell the project. This also adds to the authenticity. Can you provide a real audience or links to the professional world? Try to engage professionals in the exercise, either through masterclasses or workshops. Create opportunities that do not exist on the standard curriculum with people from outside the university.

\section{SCHEDULE TIME FOR EVALUATION AND FEEDBACK:}


Incorporate a structure for evaluation and feedback, both in the run-up to and during the exercise. See Beard and Wilson (2013: 64) for details on how to incorporate effective coaching. Make sure there is an adequate de-brief, preferably in person.

\section{TO ASSESS OR NOT ASSESS?}

You will need large numbers of staff involved to assess the project. Consider assessment methods that provoke real reflection e.g. a portfolio or logbook produced during the exercise, but submitted a few weeks afterwards is probably best (see Mathews and Heathman, 2014). Such an exercise will really encourage learners to reflect on their experience. See Beard and Wilson (2013: 69) for examples of questions that could be asked.

\section{Conclusion: it's as real as it gets}

This article has set out to define and evaluate a pedagogic method with 'high potential' for experiential learning in the classroom turned newsroom (Gentry, 1990: 19). It acknowledges the benefits and complexities of the experiential cycle, including the need to allow individual engagement and reflection. It is also suggested that educators can enhance and encourage 'experience' in the classroom by creating a more professional and authentic environment, according to a spectrum, which acknowledges the complexities of reality (Beard and Wilson, 2013). The fact that students involved in US 2012 engaged to such a large extent with the real world created a fulfilling and worthwhile experience for them. The extent to which this can be transformed into meaningful learning, however, is difficult to quantify. The holistic nature of experiential learning means that what is learned, or even 'unlearned' (Moon, 2004: 113), remains largely subjective. Perhaps the only assurance is that the active nature of the experiential process will ensure that learning occurs, though there no guarantees. This is even more reason to facilitate an 'experience' effectively, and reality or authenticity is just one aspect of this.

The US 2012 exercise adapted a so called 'live case' methodology, which encapsulated a high degree of application and a certain level of structure and allowed for the 'variety and uncertainty' (AACSB cited in Carter et al., 1986: 3) or the 'risk' (Beard and Wilson, 2013: 131) of reality to intervene. The sense of jeopardy involved empowered students to reflect on and evaluate their individual experiences in light of their own learning styles. 
As one student commented, "This is as real as it gets!"

\section{References}

Andersen, L, Boud, D. and Cohen, R. (2000). Experience Based Learning in Foley G, (Ed.), Understanding Adult Education and Training, 2nd Edition. Crows Nest, New South Wales: Allen and Unwin.

Beard, C. (2010). The Experiential Learning Toolkit: Blending Practice with Concepts. London: Kogan Page.

Beard, C. and Wilson, J. (2013). Experiential Learning: A handbook for education, training and coaching. London: Kogan Page

Boud, D. and Walker, D. (2000). Barriers to Experience, in Boud, D., Cohen, R., and Walker, D. (Eds.), Using Experience for Learning (pp. 73-86). Milton Keynes: Open University Press.

Boud, D. and Walker, D. (1990). 'Making the Most of Experience', Studies in Continuing Education, 12, pp. 61-80.

Boud D, Keogh, R. and Walker, D. (1985) (Eds.). Reflection: Turning Experience into Learning. London: Kogan Page.

Brandon, W. (2002). 'Experiential Learning: A News Study Research Path to the Study of Journalism Education' in Journalism and Mass Communication Educator, Spring, pp. 59-66.

Broadcast Journalism Training Council, The BJTC (2014). Website accessed June 2014, available at: www.bjtc.org.uk

Burnard, P. (2002). Learning Human Skills. An Experiential approach and Reflective Guide for Nurses and Health Care Professionals. 4th edition. Oxford: Butterworth-Heinemann.

Burnard, P. (1991). Experiential Learning in Action. Avebury: Ashgate.

Carter, P., Hickman, J., McDonald, P., Patton, R., and Powell, D.C. (1986). 'Memorandum on Applied and Experiential Learning Curriculum Development', AACSB Task Force Report, March.

Cass, P. (2002). 'Baptism of fire. How Journalism Students from the University of the South Pacific covered the Speight Putsch and its Aftermath', The Round Table (366), pp559-574. DOI: 10.1080/0035853022000012580.

Criticos, C. (2000). Experiential learning and social transformation for a postapartheid learning future, in Boud. D., Cohen, R., and Walker, D. (Eds.). Using Experience from Learning. Milton Keynes: Open University Press.

Cowan, J. (1998). On Becoming an Innovative University Teacher. Milton Keynes: Open University Press.

Davies, L. (1990). Experience Based Learning Within the Curriculum. London: Council for National Academic Awards.

Davies, J. and Easterby-Smith, M. (1984). 'Learning and Developing from Work Experiences', Journal of Management Studies, 21(2), 167-183.

Dennison, B. and Kirk, R. (1990). Do, Review, Learn, Apply. Oxford: Blackwell

Denscombe, M., (2007). The Good Research Guide: For Small-scale Social Research. Buckingham: Open University Press

Dewey, J. (1938). Experience and Education. New York: Collier

Dewey, J. and Dewey, E. (1915). Schools of Tomorrow. Whitefish: Kessinger

Fazey, J. and Marton, F. (2002). 'Understanding the Space of Experiential Variation', Active Learning in Higher Education, 3(3), pp. 234-50. 
Feldman, B.J (1995). 'Journalism Career Paths and Experiential Learning', Journalism and Mass Communication Educator, Summer, pp. 95-29.

Gentry, J.W. (1990). 'What is experiential learning?' in Guide to Business Gaming and Experiential Learning, Gentry, J.W. (Ed.). East Brunswick/London: Nichols Publishing.

Gibbs, G. (1988). Learning by Doing: A Guide to Teaching and Learning Methods. Oxford: Further Education Unit, Oxford Polytechnic.

Gibbons, M. and Hopkins, D. (1985). 'How Experiential is Your Experience-Based Program?' in Kraft, R. J. and Sakofs, M. (Eds.), The Theory of Experiential Education. Boulder, CO: Association for Experiential Education.

Honey, P. (1992). 'Learning from Experience: the Key to Management Development' in Frantzreb, R.B. (Ed.), Training and Development Yearbook. Englewood Cliff, NJ: Prentice Hall.

Hughes, R. (1994). 'A Critical Evaluation of the Use of Andragogical Models in Tackling Social Inequality in Nursing Education', Journal of Advanced Nursing, Vol. 20, pp. 1011-7.

Jarvis, P. (1987). Adult Learning in the Social Context. London: Croom Helm.

Jarvis, P., Holford, J., and Griffin, C. (2003). The Theory and Practice of Learning. London: Kogan Page.

Kolb, D. (1984). Experiential Learning. Experience as the Source of Learning and Development. Englewood Cliffs. NJ: Prentice Hall.

Kolb, D., Boyatzis, R.E. and Mainemelis, C. (2000). 'Experiential Learning Theory: Previous Research and New Directions’ in Sternberg R.J. and Zhang, L.F. (Eds.), Perspectives on cognitive, learning and thinking styles. New Jersey: Lawrence Erlbaum, 2000.

Kraeplin, C. and Criado, C.A. (2005). 'Building a Case for Convergence Journalism Curriculum', Journalism and Communication Educator, 60, pp.47-56 DOI: 10.1177/107769580506000109.

Lamb, Y. R., Sturgis, I. and Fancher Charles, B. (2010). 'Teaching Converged Media through News Coverage of the 2008 US Presidential Election and Inauguration' in Asia Pacific Media Educator, 20, pp. 91-102.

McGill, I. and Warner Weil, S. (1989). 'Continuing the Dialogue: New Possibilities for experiential learning', in Warner Weil, S. and McGill, I. (Eds.) Making Sense of Experiential Learning (pp. 245-74). Milton Keynes: Open University Press.

McGill, I. and Brockbank, A. (2004). The Action Learning Handbook. London: Routledge Farmer.

Mann, S. and Robinson, A. (2009). 'Boredom in the lecture theatre: an investigation into the contributors, moderators and outcomes of boredom amongst university students, British Educational Research Journal, 35: pp. 243-258

Maranville, D. (2001). 'Infusing Passion and Context into the Traditional Law Curriculum through Experiential Learning’, Journal of Legal Education, 51(1), pp. 15-24.

Marsick, V. and Watkins, K. (1990). Informal and Incidental Learning in the Workplace. London: Routledge.

Mathews, J. and Heathman, K. (2014). 'Workplace not workshop: student reflections on the introduction of a work-based approach to the final year of Journalism', Innovations in Practice 9(1), pp. 69-78

Moon, J. (2004). A Handbook of Refelctive and Experiential Learning: Theory and Practice. London: Routledge Farmer 
Moon, J. (1991). Reflection in Learning and Professional Development: Theory and Practice. London: Kogan Page.

Newman, M. (1999). Maeler's Regard. Sydney: Stewart Victor Publishing

Rhodes, L. and Roessner, A. (2008). 'Teaching Magazine Publishing through Experiential Learning’, Journalism and Mass Communication Educator, 63, pp. 303-316.

Robinson, S. (2013). 'Teaching “Journalism as Process”: a Proposed Paradigm for JSchool Curricula in the Digital Age', Teaching Journalism and Mass Communication, 3 (1), pp.1-12.

Rowland, S. (2000). The Enquiring University Teacher. Milton Keynes: Open University Press.

Schön, D. (1987). Educating the Reflective Practitioner. San Francisco: Jossey Bass.

Seaman, J. and Rheingold, A. (2013). 'Circle Talks as Situated Experiential Learning: Context, Identity, and Knowledgeability in 'Learning from Reflection', Journal of Experiential Education, 36(2), pp. 155-174.

Silberman, M. (2007). The Handbook of Experiential Learning. San Francisco: John Wiley and Sons.

Snell, R. (1992). 'Experiential Learning at Work: Why Can’t it be Painless?, Personnel Review, 21(4), pp. 12-26

Steel, J., Carmichael, B., Holmes, D., Kinse, M., and Sanders, K. (2007). 'Experiential Learning and Journalism Education. Lessons Learned in the Practice of Teaching Journalism', Education and Training, 49 (4), pp. 325334.

Vygotsky, L. S. (1978). Mind in Society: The Development of Higher Psychological Processes. Cambridge, MA: Harvard University Press.

Wolfe, D.E. and Byrne, E.T. (1976). Experience Based Learning in Business Education' in Houston, Cooper J.M. and Warner A.R. (Eds.), Clinical practice in teacher education. Houston, TX: University of Houston. 